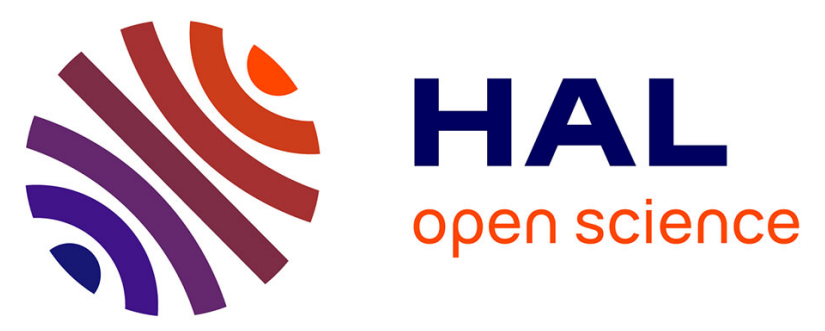

\title{
Assessing the narrowband to broadband conversion to estimate visible, near infrared and shortwave apparent albedo from airborne POLDER data
}

Frédéric Jacob, M. Weiss, Albert Olioso, Alice French

\section{- To cite this version:}

Frédéric Jacob, M. Weiss, Albert Olioso, Alice French. Assessing the narrowband to broadband conversion to estimate visible, near infrared and shortwave apparent albedo from airborne POLDER data. Agronomie, 2002, 22 (6), pp.537-546. 10.1051/agro:2002049 . hal-02672973

\section{HAL Id: hal-02672973 \\ https://hal.inrae.fr/hal-02672973}

Submitted on 5 Nov 2021

HAL is a multi-disciplinary open access archive for the deposit and dissemination of scientific research documents, whether they are published or not. The documents may come from teaching and research institutions in France or abroad, or from public or private research centers.
L'archive ouverte pluridisciplinaire HAL, est destinée au dépôt et à la diffusion de documents scientifiques de niveau recherche, publiés ou non, émanant des établissements d'enseignement et de recherche français ou étrangers, des laboratoires publics ou privés. 
Agronomie: Agriculture and Environment

\title{
Assessing the narrowband to broadband conversion to estimate visible, near infrared and shortwave apparent albedo from airborne PolDER data
}

\author{
F. Jacob ${ }^{* a}$, M. Weiss ${ }^{\text {b }}$, A. Olioso ${ }^{\text {b }}$, A. French ${ }^{\text {a }}$
}

${ }^{a}$ USDA/ARS Hydrology and Remote Sensing Laboratory,

Bldg 007, BARC-West, Beltsville, MD 20705-2350, USA

b INRA Climat-Sol-Environnement,

Domaine St Paul, Site Agroparc, 84914 Avignon Cedex 9, France

* Corresponding author :

Phone: (1) 301-504-6142

Fax: (1) 301-504-8931

Email: fjacob@hydrolab.arsusda.gov 


\begin{abstract}
The airborne PolDER data acquired during the ReSeDA experiment were used to assess the accuracy of the narrowband to broadband conversion, commonly used to express the integrated value of albedo as a linear function of waveband estimates. We focused on the estimation of shortwave, visible and near infrared apparent albedos from waveband hemispherical reflectances. The latter were computed using four classical linear BRDF kernel-driven models. The relative discrepancy over the estimates from the four models was about $10 \%$. The narrowband to broadband conversion was performed considering several coefficient sets devoted to recent sensors. The validation against field measurements showed a relative accuracy of shortwave albedo about $9 \%$, whereas it emphasized the quality of visible and near infrared albedos through an indirect procedure. However, the consequences of the theoretical uncertainties, made when calibrating the coefficient sets we used, remain unknown. Similarly, the calibration of coefficient sets devoted to the shortwave albedo estimation from PolDER data showed that it was not possible to discriminate the information provided by the blue, green and red PolDER channels. Indeed, the hemispherical reflectance data set we used was not accurate enough to address experimentally the validity of the spectral interpolation method. Finally, the calibration of coefficients showed that it might be possible to calculate shortwave albedo with a relative error of $8 \%$ using only red and near infrared channels.
\end{abstract}

remote sensing / multidirectional \& multispectral data / visible - near infrared - shortwave apparent albedo / narrowband to broadband conversion. 
Titre: Évaluation de la méthode "narrowband to broadband conversion" pour estimer l'albedo apparent visible - proche infrarouge - courtes longueurs d'onde à partir de données aéroportées PolDER.

Résumé - Les données aéroportées PolDER acquises durant l'expérimentation ReSeDA ont été utilisées pour évaluer la précision de la méthode "narrowband to broadband conversion", communément utilisée pour exprimer la valeur intégrée de l'albedo comme une combinaison linéaire de mesures spectrales. Nous nous sommes intéresses à l'estimation de l'albedo apparent visible - proche infrarouge courtes longueurs d'onde à partir de la réflectance hémisphérique. Cette dernière a été calculée en utilisant quatre modèles classiques de FDRB à noyaux. La dispersion relative entre les estimations des quatre modèles était de l'ordre de $10 \%$. Nous avons calculé la valeur integrée de l'albédo en utilisant des jeux de coefficients proposés dans la littérature pour des capteurs récents. La validation a montré que l'albedo courtes longueurs d'onde PolDER avait une précision relative de l'ordre de 9\%, alors qu'une procédure indirecte a mis en évidence la qualité des albedo visible et proche infrarouge. Cependant, les estimations de réflectance hémisphérique n'étaient pas assez précises pour évaluer les conséquences des incertitudes théoriques des jeux de coefficients. De même, la calibration de jeux de coefficient à l'aide des données ReSeDA a montré qu'il n'était pas possible de discriminer l'information fournie par les canaux PolDER bleu, vert et rouge. Finalement, il était possible de calculer l'albedo avec une précision relative de $8 \%$ en ne considerant que les canaux rouge et proche infrarouge.

télédétection / données multidirectionnelles et multispectrales / albedo apparent visible - proche infrarouge - courtes longueurs d'onde / narrowband to broadband conversion 


\section{Introduction}

Instantaneous surface albedo is defined as the fraction of incident solar radiation reflected in all directions over a given spectral range of the solar spectrum. Subdefinitions are proposed according to the consideration of the spectral range and the consideration of the diffuse and / or the direct components of incoming solar radiation [16]. Shortwave, visible and near infrared albedos correspond respectively to the whole solar spectrum, the $[400-700] \mathrm{nm}$ and the $[700-5000] \mathrm{nm}$ spectral ranges. Inherent (or black-sky), white-sky and apparent albedo correspond respectively to the direct component of incoming solar radiation, the diffuse component and both of them. Knowledge of these kinds of albedo in a spatially distributed manner is of prime interest for global climate modeling [7], meteorological studies $[3,5]$, and surface flux estimation $[13,22,10]$. The required accuracy varies from one application to another. Sellers [29] suggested a relative accuracy of $\pm 2 \%$, whereas GCM studies and weather forecast modeling require an absolute accuracy of $\pm 5 \%$ that corresponds to a relative accuracy of $\pm 10 \%$ [4].

Remote sensing is the most promising technique to estimate surface albedo in a spatially distributed manner. However, such a technique requires extrapolating the spectral and angular information collected from observations in a limited number of both viewing directions and wavebands. One possible approach is to express the spectrally integrated value of the albedo as a linear combination of top of canopy or top of atmosphere bidirectional reflectance using coefficient sets calibrated over simulated or measured data sets $[2,30,39,16,15]$. Obviously, it is better to use top of canopy bidirectional reflectance to avoid the noise induced by the atmosphere variability. However, the accuracy of this method is limited by the representativeness of a single directional observation regarding to the angular variation of the reflected solar energy, so called BRDF for Bidirectional Reflectance 
Distribution Function [36]. Therefore, another approach consists in considering hemispherical reflectance, rather than bidirectional reflectance, when computing the integrated value of albedo as a linear combination of wavebands estimates [39]. This requires first characterizing the BRDF, which can be performed by processing the multidirectional information using either radiative transfer models $[24,12]$ or kernel-driven models [38, 18].

During the ReSeDA experiment, visible - near infrared remote sensing data were acquired using the airborne multiangular PolDER radiometer, simultaneously with field measurements of albedo. The PolDER / ReSeDA data set provided an opportunity to assess the potential of the narrowband to broadband conversion. First, it covered the whole cycles of different crops including winter and summer ones. Second, the use of high spatial resolution remote sensing data reduced problems due to mixed pixels. Previous studies assessed the performances of classical kernel-driven models to both characterize the BRDF and estimate the hemispherical reflectance from this data set. Weiss et al. [40] analyzed the importance of the kernel number, as well as the impact of the directional sampling through both the number of data and their angular distribution regarding to the sun position. Jacob et al. [11] assessed the impact of the spatial variability, the atmospheric conditions and the waveband. They also evaluated the variability of the hemispherical reflectance estimates when considering several kernel-driven models, and its possible link with the fitting performances.

In this study, we focused on the estimation of the spectrally integrated value of visible, near infrared and shortwave albedo using top of canopy estimates of hemispherical reflectance in several wavebands. As mentioned previously, this narrowband to broadband conversion is generally performed using coefficient sets calibrated over simulated or measured data sets. We considered and compared several 
coefficient sets devoted to recent sensors, and calibrated over data sets that differed spectrally, directionally and experimentally. We also assessed the possibility to perform a coefficient calibration using the ReSeDA database. After presentation of the airborne and field data, we review the important results we obtained before when evaluating the performances of the kernel-driven models [11]. Next, we discuss the results of both the intercomparison and the validation of the albedo estimates. Finally, we propose coefficient sets calibrated over the ReSeDA database, and devoted to shortwave albedo estimation from airborne PolDER data. The quality of these coefficients is discussed by assessing their statistical and physical meanings.

\section{Data acquisition and preprocessing}

The ReSeDA experiment lasted from December 1996 to December 1997, in the South East of France (N $43^{\circ} 47^{\prime}$, E $\left.4^{\circ} 45^{\prime}\right)$. The experimental site was a $5 \times 5 \mathrm{~km}^{2}$ agricultural region with maize, sunflower, wheat and alfalfa fields about $200 \times 200 \mathrm{~m}^{2}$ size $[26,23]$. In this study, we used both the airborne PolDER measurements and the field data of albedo. The following is an overview of the PolDER and in-situ data acquisition and preprocessing. More detailed descriptions are given by Leroy and Hautecoeur [14], Olioso et al. [21], and Francois et al. [9].

The airborne PolDER sensor [6] flew approximately one or two times per month during the year 1997, on clear sky days, at a $3000 \mathrm{~m}$ altitude resulting in a $20 \mathrm{~m}$ nadir spatial resolution. Four flight lines were parallel to the solar plane, and one perpendicular. The five lines were completed within 45 minutes centered around solar noon. The measurements were collected in four $40 \mathrm{~nm}$ width wavebands centered at $443 \mathrm{~nm}, 550 \mathrm{~nm}, 670 \mathrm{~nm}$, and $865 \mathrm{~nm}$. View zenith angle ranged from 0 to $50^{\circ}$. Data were radiometrically corrected in a similar way than that used by Leroy and Hautecoeur [14]. The sensor calibration was performed by the Lab- 
oratoire d'Optique Atmophérique (Lille, France) three times: before, during and after the experiment. The procedure accounted for ambient temperature, dark current, and the inter-calibration of the CCD matrix detectors. Calibration accuracy was about 5\%. Atmospheric effects were corrected using the SMAC algorithm [27]. The input atmospheric variables were field measurements or climatological data of aerosol optical thickness, water vapor content and ozone concentration. No accuracy was proposed for these corrections. Image registration was performed using data provided by both a Global Positioning System and a gyroscopic central unit. The images were geometrically matched according to a Lambert II projection that provided a $20 \mathrm{~m}$ spatial sampling of the study area. This preprocessing provided a data base of BRDF samplings, i.e. a pixel by pixel set of measurements of the reflected solar energy in a selection of viewing directions for each PolDER waveband. Each measurements was the sum of the reflected fractions of incident direct and diffuse radiations, these fractions being weighted by the amount of the corresponding energy.

Ground based observations of albedo were estimated as the ratio of reflected to incident solar radiation measurements. The incident solar radiation was measured using a Kipp \& Zonen CM6B pyranometer setup at the meteorological site located at the center of the experimental area. The reflected solar radiation was measured on seven locations corresponding to alfalfa, wheat, and sunflower crops using either Kipp \& Zonen CM6B pyranometers or Skye Instruments SP1110 silicon sensors. These routine data were collected with both a $15 \mathrm{~s}$ time step and a $20 \mathrm{mn}$ period averaging. The corresponding footprint ranged from 1000 to $3000 \mathrm{~m}^{2}$. The intercalibration of the Kipp sensors provided a residual error about $10 \mathrm{~W} . \mathrm{m}^{-2}$, which yielded a relative error on computed albedo of $1.5 \%$. The Kipp sensors were calibrated to provide estimates of the incoming solar radiation over the whole solar 
spectrum from measurements over the [300-3000] nm range. The Skye sensors measured the incoming solar radiation over the [350-1100] nm spectral band. The extrapolation of the Skye data to the whole solar spectrum required accounting for the spectral reflectance variations of the observed surfaces. For this, we calibrated a formulation between simulated Skye and Kipp albedo around solar noon. The simulations were performed by Francois et al. [9] using the radiative transfer model SAIL [33]. The SAIL inputs were soil / leaf optical properties, measurements of Leaf Area Index, and spectra of incident solar radiation computed from simulations of the atmospheric radiative transfer model 6S [34] that included numerous atmospheric situations. These simulations are described in details by Francois et al. [9]. The formulation we calibrated was linear with a residual error of 0.003 :

$$
\text { Albedo }_{\text {actual }}=0.785 \times \text { Albedo }_{\text {Skye }}+0.02
$$

\section{Hemispherical reflectance estimation: an overview.}

A detailed discussion about the choice of the kernel-driven models used and the results obtained when assessing their performances is given by Jacob et al. [11]. We only give here an overview of the most important results, and some concluding remarks that were useful for the present study. The chosen models were four classical three-kernel-driven models: Li-Ross in the "Li-Sparse / Ross-Thick" variant [37], the semi-linearized version of MRPV [8], Roujean [28], and the non reciprocal version of Walthall [35]. Model performances were assessed considering PolDER data acquired over the in-situ data locations. It was shown that the fitting performances were not affected by the atmospheric conditions and were very close from one model to another regardless of waveband. These performances decreased systematically as the wavelength increased. This was explained by the aerosol diffusion, which induced at shorter wavelengths a lower signal to noise 
ratio, as well as a higher diffuse component not adequately described by the models. On the other hand, the hemispherical reflectance estimates were significantly different from one model to another. The most important differences occurred over the blue channel. Apart from this waveband, the agreement between the estimates was not systematically better as the wavelength increased. This showed that the fitting performances and the quality of the hemispherical reflectance estimates were not completely correlated, which emphasized the importance of the model interpolation performances. Finally, as noted previously by Privette et al. [25] and Lucht [17], the inter-comparison of the estimates showed that the hemispherical reflectance values could be significantly different from one model to another, with a relative discrepancy of about 10\% (discrepancy expressed as the ARMSD and $\mathrm{RRMSD}^{1}$, see Table 1). A detailed discussion about these results is given by Jacob et al. [11].

[Table 1 about here.]

Before using these hemispherical reflectance estimates to compute albedo, we rejected unrealistic values lower than 0 or higher than 1 . These unrealistic values were ascribed to noise occurring on the data set of sampled BRDF. Table 2 displays the rejection rate over the whole study area apart from the mountain chain located at the south since the models were not designed for inclined areas. As a consequence of the perturbations we noted before, the rejection was systematically and significantly more important over the blue channel. Regardless of kernel-driven model, the lowest occurrence of unrealistic values corresponded to the near infrared channel, while this occurrence was similar over the green and red channels, and slightly higher at $670 \mathrm{~nm}$. When considering the robustness to noise of each kernel-driven

\footnotetext{
${ }^{1}$ The ARMSD (Absolute Root Mean Square Difference) is the mean quadratic error between two predicted or observed variables. The RRMSD (Relative Root Mean Square Difference) is the ratio of the ARMSD to the average of the predicted or the observed values respectively.
} 
model, we noted that Roujean provided systematically the highest number of unrealistic values regardless of PolDER wavebands. The best robustness was observed for MRPV while the results we obtained with Li-Ross were also good as compared to Roujean and Walthall. These observations were important since they emphasized that the kernel-driven models we used could not provide systematically realistic values and could not therefore be used confidently in an operational manner. Furthermore, the recommendation of a kernel-driven model should be a compromise between the accuracy of the model and its robustness regarding to the noise occurring over the used data set. For further investigations, we selected PolDER data acquired over the in-situ data locations.

[Table 2 about here.]

\section{Estimating broadband apparent albedo from multispec- tral data}

All the subdefinitions of albedo $a\left(\theta_{s}, \varphi_{s}\right)$ given in Section 1 can be expressed as weighted integrations of the hemispherical reflectance $\rho_{h, \lambda}\left(\theta_{s}, \varphi_{s}\right)$ over the considered spectral range, where the hemispherical reflectance is related to the diffuse component, and / or the direct component of the incoming solar radiation. As explained previously, the narrowband to broadband conversion consists in expressing the integrated value as a linear combination of the wavebands hemispherical reflectance $\rho_{h, \lambda_{j}}\left(\theta_{s}, \varphi_{s}\right)$ over the PolDER channels $j$.

$$
a\left(\theta_{s}, \varphi_{s}\right)=\beta_{0}+\sum_{j=1}^{4} \beta_{j} \cdot \rho_{h, \lambda_{j}}\left(\theta_{s}, \varphi_{s}\right)
$$

Since coefficient sets $\left(\beta_{j}\right)$ devoted to the airborne PolDER sensor did not exist, despite a study focused on the spaceborne version [15], we selected among the several sets suggested in the literature some proposed in recent studies: 3 by 
Weiss et al. [39] for generic sensors, and 6 by Liang et al. [16] and Liang [15] for the MISR sensor (see Table 3). They were devoted to atmospherically corrected data.

Weiss et al. [39] proposed three sets obtained from linear regressions between simulated hemispherical reflectance and shortwave apparent albedo. The simulations were performed between 400 and $2500 \mathrm{~nm}$ with the radiative transfer model developed by Myneni et al. [20]. They were representative of several kinds of canopies at different latitudes and different seasons. These three sets differed by the number of used channels among the blue, green, red and near infrared spectral domains. Sets $n^{0} 2$ and $n^{0} 3$ were very similar. However, we used both of them since they could provide different results according to the hemispherical reflectance estimates in the blue and red channels.

Liang et al. [16] proposed sets dedicated to the shortwave, visible and near infrared inherent albedo using MISR data. The coefficients were computed from linear regressions over more than 100 observed reflectance spectra between 200 and $3000 \mathrm{~nm}$ that corresponded to vegetation, soil and snow. This study was extended by Liang [15] who calibrated sets to compute shortwave, visible and near infrared apparent albedo, considering up to 256 spectra ranging between 250 and $2500 \mathrm{~nm}$ and derived from field and airborne measurements over numerous surfaces. We should note that Liang et al. [16] and Liang [15] used directional measurements by assuming the surfaces were Lambertian, which could be far from actual situations. Moreover, the coefficient sets proposed by Liang et al. [16] for the MISR sensor were dedicated to the estimation of inherent albedo whereas we focused in this study on apparent albedo. Nevertheless, we decided to test these sets in order to assess the possible discrimination of these two kinds of albedo regarding to the experimental context and the resulting inaccuracies. 
[Table 3 about here.]

Visible, near infrared and shortwave albedo calculations were performed considering the several combinations between the kernel-driven models and the coefficient sets. The shortwave albedo maps depicted values between 0.1 and 0.4. This variability was explained by the simultaneous presence of vegetative surfaces and bare soils over the site.

\subsection{Intercomparison of albedo estimates}

We first compared apparent and inherent albedos. Regardless of kernel-driven model, apparent and inherent albedos were very close over the visible domain (ARMSD between albedo from sets $\mathrm{n}^{\mathrm{O}} 4$ and 7 of 0.0013 corresponding to a RRMSD of $1.4 \%$ ) and significantly different over the near infrared domain (ARMSD between albedo from sets $n^{0} 5$ and 8 of 0.0470 corresponding to a RRMSD of $14.4 \%$ ). These results were consistent with the simulation study of Liang [15], and could be explained by a higher sensitivity of near infrared white sky and therefore apparent albedo to the atmospheric conditions. The sensitivity of the inherent and apparent albedo products to the choice of a kernel-driven model was more important over the visible domain (ARMSD between two estimates ranging from 0.0067 to 0.0137 corresponding to RRMSD ranging from 7.0 to $13.5 \%$ ) than over the near infrared range (ARMSD between two estimates ranging from 0.0080 to 0.0240 corresponding to RRMSD ranging from 2.2 to $7.5 \%$ ). Possible explanations were 1) a lower signal to noise ratio for visible albedo and 2) the contribution of the diffuse component that was more important over the visible domain and not well described by the kernel-driven models. Indeed, the contribution of the blue channel was significant when using sets $\mathrm{n}^{\mathrm{O}} 4$ and 7 , whereas we noted previously that the discrepancy between hemispherical reflectance estimates from the different kernel-driven models 
was important at $443 \mathrm{~nm}$. Finally, we verified that apparent visible, near infrared and shortwave albedos were consistent by computing the ABias ${ }^{3}$ between each other. As expected for canopies and soils, visible albedos were lower than shortwave albedos (ABias about -0.1020) that were lower than near infrared albedos (ABias about -0.1044).

The comparison of inherent or apparent shortwave albedos for a given coefficient set showed that the values were systematically close from one kernel-driven model to another (an example is given in Table 4). On the other hand, the estimates for a given kernel-driven model could be significantly different from one coefficient set to another when considering sets devoted to the apparent albedo (an example is given in Table 5). This emphasized that the method we used to compute apparent shortwave albedo was more sensitive to the choice of a coefficient set than to the choice of a kernel-driven model. Moreover, the difference we obtained when comparing two different sets dedicated to apparent albedo $\left(\operatorname{set}^{0} 1\right.$ and 2 for example) could be more important than the difference between inherent and apparent estimates ( $\operatorname{set}^{\mathrm{o}} 6$ and 9 for example). A possible explanation was the theoretical inaccuracy of the coefficient sets we used and / or both the theoretical and experimental inaccuracies of the hemispherical reflectance estimates. Besides, the difference between shortwave apparent and inherent albedos could be small since the PolDER data were collected under clear sky conditions that might correspond to a low diffuse component of incoming solar radiation. Finally, we should note that sets $\mathrm{n}^{\mathrm{O}} 2$ and 3 provided very close results, which indicated that it was possible to avoid the use of the blue channel over which significant perturbations occurred.

[Table 4 about here.]

\footnotetext{
${ }^{3}$ The ABias (Absolute Bias) is the averaged difference between either 1) two predicted variables or 2) observed and predicted variables. The RBias (Relative Bias) is the ratio of the ABias to the average of either 1) the predicted values or 2) the observed values.
} 
[Table 5 about here.]

\subsection{Validation of albedo estimates}

The comparison of the airborne estimates against field measurements required accounting for the spatial, temporal and spectral features of both the PolDER and in-situ data. Accounting for the spatial features consisted in assessing the influence of the spatial variability over the $400 \mathrm{~m}^{2}$ size PolDER estimates that were compared against 1000 to $3000 \mathrm{~m}^{2}$ size field data. This was performed by computing the coefficient of variation (standard deviation / mean value) inside both $3 \times 3$ and $5 \times 5$ PolDER pixel windows. The coefficient of variation ranged between 1 and $2 \%$, which emphasized the negligible effect of the spatial variability around field measurement locations. Therefore, we decided to perform the validation by extracting PolDER estimates through $3 \times 3$ pixel windows. Accounting for the temporal features consisted in averaging the field data over the period of the PolDER data acquisition that was about 45 minutes. Accounting for the spectral features when validating PolDER visible and near infrared albedos consisted in computing shortwave albedo $a_{\text {short }}$ from visible $a_{v i s}$ and near infrared $a_{N I R}$ values in order to perform a comparison with the shortwave field estimates. This was performed by expressing $a_{\text {short }}$ as a weighted summation of $a_{v i s}$ and $a_{N I R}$ :

$$
a_{\text {short }}=k \cdot a_{v i s}+(1-k) \cdot a_{N I R}
$$

where $k$ is the ratio of the incident radiation over the [400 - 700] $\mathrm{nm}$ spectral domain to the whole solar spectrum. The proposed values in the literature range between 42 and 51\% [32]. Accounting for ultraviolet radiation and assuming that surface albedos are quite similar over the ultraviolet and the visible domains increases $k$ by about $5 \%$. Therefore, we performed the validation by considering $k$ values between 0.47 and 0.56 . 
Examples of validation using shortwave or visible \& near infrared coefficient sets are given in Figs. 1 and 2. They illustrate the best results that corresponded to the Li-Ross model with set $n^{\circ} 6$, and the Walthall model with both sets $n^{0} 7$ and 8 and a $k$ value about 0.55 . These comparisons showed that there were no differences between Kipp and Skye estimates after the corrections of the latter (Sect.2). We should note that the number of validation plots were not the same from one model to another. This was a consequence of the rejection filter applied to the unrealistic hemispherical reflectance values, which was discussed in the part of this study dealing with the directional issue.

[Figure 1 about here.]

[Figure 2 about here.]

For all the possibilities, we computed both the ABias / RBias and the ARMSE / RRMSE between airborne and field estimates (an example is given in Table 6). Sets $n^{0} 1,2,3$ and 9 overestimated the field measurements regardless of kerneldriven model. One could think in a first time that the overestimation provided by sets $n^{0} 1,2,3$ could result from the spectral domain Weiss et al. [39] used to calibrate these sets, as suggested by Jacob et al. [11]. Nevertheless, the results we obtained with sets $n^{\circ} 6$ and 9 invalidated this explanation. Indeed, these two sets were calibrated over similar spectral ranges that were different from that used by Weiss et al. [39]. However, set $n^{\circ} 9$ induced a similar overestimation than sets $n^{0} 2 / 3$ whereas set $n^{\circ} 6$ provided very small over- or under- estimations. Besides, set $n^{\circ} 6$ provided the best validation results regardless of kernel-driven model, whereas it was devoted to the estimation of inherent albedo. We should also note that

\footnotetext{
${ }^{1}$ The ARMSE (Absolute Root Mean Square Error) is the mean quadratic error between predicted and observed variables. The RRMSE (Relative Root Mean Square Error) is the ratio of the ARMSE to the average of the observed values.
} 
sets $n^{\circ} 6 / 9$ were calibrated using bidirectional reflectance whereas we expected best results when considering hemispherical reflectance such as sets $n^{0} 1$ to 3 . Moreover, we obtained similar results with set $\mathrm{n}^{\mathrm{O}} 3$ and 9 whereas they were derived considering different sensor spectral wavebands. All these observations showed that the experimental inaccuracies of the hemispherical reflectance estimates (about 5\% at least on the radiometric processing and $10 \%$ of relative discrepancy over the estimates from the four kernel-driven models) were too important to isolate the errors induced by the theoretical assumptions made when calibrating the coefficient sets dedicated to shortwave albedo. Moreover, the comparison was difficult since it was not possible to separate the different factors. For instance, set $n^{0} 1$ to 3 could induce an overestimation because of the spectral domain chosen for the calibration as suggested by Jacob et al. [11]; whereas the overestimation from set $n^{\circ} 9$ could result from the use of bidirectional reflectance data to perform the calibration, since bidirectional reflectance is often higher than hemispherical reflectance.

The validation of shortwave albedo estimates through the visible and near infrared values using both couples ( $\operatorname{sets~}^{\circ} 4$ and 5) and ( $\operatorname{sets~}^{0} 7$ and 8) showed that regardless of $k$ value between 0.47 and 0.56 , the best estimates were provided by the coefficient sets dedicated to apparent albedo (i.e. sets $n^{0} 7$ and 8). This might be explained by the necessity to well characterize the apparent albedo when distinguishing the visible and near infrared components. Indeed, near infrared white sky and therefore apparent albedo was more sensitive to the atmospheric conditions as mentioned previously. Furthermore, it was difficult to conclude about the quality of the visible and near infrared estimates since the validation was indirect and depended on $k$ values that varied according to the meteorological conditions. We could only mention that the shortwave estimates were close to the field measurements when considering a $k$ value about 0.55 , which agreed with the value pro- 
posed by Varlet-Grancher et al. [32] when considering the French national scale. Besides, the validation results varied significantly according to this ratio, with a RRMSE ranging from $8.5 \%(k=0.55)$ to $15 \%(k=0.47)$. Such a variation emphasized the importance of this parameter when deriving shortwave albedo from visible and near infrared ones.

When validating the shortwave albedo estimates for a given coefficient set, we noted that the best estimates corresponded systematically to both Li-Ross and Walthall models, with slightly better results for Walthall (an example is given in Table 7). The results we obtained with Walthall were consistent with previous studies, and were explained by the model robustness when considering several land use situations $[31,1]$. The results we obtained with Li-Ross were also consistent with previous studies $[25,17,19]$, and could be explained by the directional performances of the "Li-Sparse / Ross-Thick" variant over vegetative areas.

[Table 6 about here.]

[Table 7 about here.]

\subsection{Calibrating coefficient sets for the narrowband to broadband con- version}

The last step of this study aimed at calibrating some coefficient sets dedicated to the estimation of shortwave apparent albedo from the airborne PolDER sensor. This was motivated by the following observations. First, no proposition existed in the literature from our knowledge regarding to the airborne PolDER spectral configuration. Second, the airborne PolDER sensor allows to acquire high spatial resolution data that can be used as reference for large scale studies and satellite product validation. Third, resulting analysis from this study showed that albedo estimation was more sensitive to the choice of a coefficient set than to the choice 
of a kernel-driven model. This emphasized the importance of the narrowband to broadband conversion.

Before performing the coefficient set calibration, we assessed the information provided by each PolDER waveband. For this, we evaluated possible redundant information by calculating the intercorrelation coefficients between the waveband estimates for 45 observations. The results we obtained when considering the LiRoss model are displayed in Table 8 . We obtained similar results with the other kernel-driven models. It was shown that only the NIR channel was not correlated to the others. Therefore, we concluded that considering two channels should be sufficient to compute albedo, whereas the use of the NIR channel was absolutely necessary. The information provided by the blue, green and red channels was quite the same, or could not be discriminated, because of the noise over the hemispherical reflectance data set. Indeed, the correlation coefficient between these channels was about 0.9 whereas the relative discrepancy when comparing the four kerneldriven models for a given waveband was about $10 \%$.

[Table 8 about here.]

The calibration of the coefficient sets was performed using a pseudo-matrix inversion between the PolDER hemispherical reflectances and the field measurements of albedo:

$$
[a]=\left[\beta_{j}\right] .\left[1 \quad \rho_{h, \lambda_{j}}\right] \quad \Longleftrightarrow \quad\left[\beta_{j}\right]=\left[\begin{array}{ll}
1 & \rho_{h, \lambda_{j}}
\end{array}\right]^{-1}[a]
$$

Moreover, we estimated the $90 \%$ confidence interval for the coefficients, as well as the residual error. The results we obtained are listed in Table 9. We only reported the results corresponding to a unique selection among the blue, green and red channels. Indeed, the results with the other selections were very similar, which was consistent with the correlation coefficients between these three bands. When 
considering only two channels, the coefficient sets were similar from one model to another, and the coefficient confidence interval ranged between 15 and $20 \%$ of the coefficient values. This emphasized once more the effect of noise occurring over the data set. Moreover, the results were physically consistent since the coefficients were positive and their sum was close to unity. Indeed, as suggested by Brest and Goward [2], the considered bands were assumed to be representative of given spectral intervals according to the surface reflectance variations, and the associated coefficients were assumed to correspond to the incoming solar radiation over these spectral ranges. When considering three or four PolDER wavebands, the results were worse despite a lower residual error. The confidence interval of the blue and green coefficients indicated that these coefficients could be equal to zero. Therefore, these channels could not be considered as noted previously. Moreover, adding the green and / or the blue channels increased significantly the uncertainty of the red coefficient. This showed that considering more than one band among the blue, green and red added more noise than information. As a consequence, the multilinear regression provided some physically unrealistic coefficients such as negative values whereas the coefficient sum was not anymore close to one, except for MRPV. Obviously, the residual error was better when considering all the bands. However, this results must be considered with many care since the fitting included the induced noise. From our results, it is recommended to consider only the red and NIR bands of the PolDER sensor. Indeed, two channels were sufficient and the red one was less noisy than the blue and green ones. However, these results depended on the observed surfaces and the accuracy of the data base we used. Indeed, more accurate hemispherical reflectance estimates may emphasize the necessity to use more spectral information. 
[Table 9 about here.]

\section{Conclusions}

The objective of this study was to assess the accuracy of the narrowband to broadband conversion when using coefficient sets to calculate the integrated value of albedo as a linear function of hemispherical reflectances. This was performed considering shortwave, visible and near infrared albedos. The data set we used was acquired in the framework of the ReSeDA program, including remote sensing data collected with the airborne PolDER sensor and simultaneous field measurements of albedo. This multitemporal and high spatial resolution data set allowed to perform comparison, validation and calibration of coefficient sets considering growth cycles of several crops while problems due to mixed pixels were reduced.

The hemispherical reflectance was estimated using four classical linear BRDF kernel-driven models: Li-Ross, MRPV, Roujean and Walthall. The intercomparison of the estimates showed a relative discrepancy of about $10 \%$. The assessment of the model abilities to provided realistic hemispherical reflectance estimates despite the effect of noise occurring on the PolDER data showed that Li-Ross and MRPV were the most robust models.

The narrowband to broadband conversion was first assessed comparing and validating several coefficient sets proposed recently in the literature. The intercomparison of visible, near infrared and shortwave albedos allowed to experimentally verify several observations previously reported in simulation studies. The intercomparison of the several shortwave albedo estimates emphasized that the method we used was more sensitive to the choice of a coefficient set than to the choice of a kernel-driven model. The validation against field measurements showed a rela- 
tive accuracy of about $9 \%$ for the shortwave apparent albedo product. This was an acceptable result regarding to the inaccuracy of the PolDER data processing that was at least about $5 \%$. However, the hemispherical reflectance estimates were not accurate enough to assess the uncertainties of the assumptions made when calibrating the coefficient sets we used. An indirect validation of the visible and near infrared albedos suggested that their quality was good, whereas it was difficult to conclude because of the procedure used that depended on the ratio of visible to shortwave radiation. Nevertheless, the ratio that provided the closest estimates to field data corresponded to the value proposed in literature when considering similar regions. Regardless of considered albedo, we noted that the best validation results corresponded to both the Li-Ross and Walthall BRDF kernel-driven models. Since Li-Ross was also one of the most robust models when assessing their abilities to provide realistic hemispherical reflectances despite noisy data, we could conclude that this model was the most interesting among the four ones we used, for both its accuracy and its feasibility.

Finally, we evaluated the possibility to calibrate coefficient sets devoted to the estimation of shortwave albedo from the airborne PolDER sensor. The calibration results showed that this was difficult when using hemispherical reflectance computed from measured data. The statistical tools and physical indicators we used to assess the quality of the calibrated coefficients emphasized the sensitivity of the method to the uncertainty of the hemispherical reflectance estimates. Indeed, the latter were not accurate enough to discriminate the information provided by the blue, green and red PolDER channels. Further investigations are necessary to provide accurate reflectance estimates that allow to experimentally address the validity of the narrowband to broadband conversion. Finally, it was possible to calculate shortwave albedo with a relative error of about $8 \%$ using only red and near infrared 
channels.

\section{Acknowledgments}

This study was performed during a post-doctoral position funded by the ASTER project of NASA's EOS-Terra Program. Financial support was provided by EC in the frame of the WATERMED project (contract ICA3-CT-1999-00015). The Alpilles / ReSeDA project was funded by the EEC-DG XII (contract ENV4-CT960326-PL952071) and the French Programme National de Télédétection Spatiale and Programme National de Recherches en Hydrologie. The PolDER airborne sensor was provided by the Laboratoire d'Optique Atmosphérique, Lille, France. 


\section{References}

[1] Baret F., Weiss M., Leroy M., Hautecoeur O., Santer R., Bégué A., Impact of surface anisotropies on the observation of optical imaging sensors, final report, ESA contract 11341/95/NL/CN, ESA, ESTEC, the Netherlands, 1997.

[2] Brest C., Goward S., Deriving surface albedo measurements from narrow band satellite data, International Journal of Remote Sensing 8 (1987) 351367.

[3] Calvet J.-C., Noilhan J., Roujean J.-L., Bessemoulin P., Cabelguenne M., Olioso A., Wigneron J.-P., An interactive vegetation SVAT model tested against data from six contrasting sites, Agricultural and Forest Meteorology 92 (1998) 73-95.

[4] Cihlar J., et al., GCOS/GTOS plan for terrestrial climate-related observations, Version 2.0., GCOS-32 WMO/TD-No 796, UNEP/DEIA/TR.97.7, GCOS Joint Planning Office, Geneva, Switzerland, 1997.

[5] Courault D., Lacarrere P., Clastre P., Lecharpentier P., Jacob F., Estimation of surface fluxes using remote sensing data and the MESONH model on the ALPILLES area, in: Remote sensing and Hydrology Symposium, Montpellier, France, 2001, Submitted.

[6] Deschamps P., Bréon F., Leroy M., Podaire A., Bricaud A. Buriez J., Sèze G., The PolDER mission : instrument characteristics and scientific objectives, IEEE Transactions on Geoscience and Remote Sensing 32 (1994) 598-615.

[7] Dickinson R., Land surface, Cambridge University Press, New York, 1992.

[8] Engelsen O., Pinty B., Verstraete M., Martonchik J., Parametric bidirectional reflectance factor models : evaluation, improvements and applications, Report EUR16426EN, European Commission, Joint Researches Center, Space Application Institute, ISPRA, Italy, 1996.

[9] François C., Ottlé C., Olioso A., Prévot L., Bruguier N., Ducros Y., Conversion of 400 - $1100 \mathrm{~nm}$ vegetation albedo measurements into total shortwave broadband albedo using a canopy radiative transfer model, Agronomie (2002) Accepted. 
[10] Jacob F., Olioso A., Gu X., Su Z., Wassenaar T., Marloie O., Hanocq J., Hautecoeur O., François C., Seguin B., Mapping surface fluxes using visible, near infrared, thermal infrared remote sensing data with a spatialized surface energy balance model, Agronomie (2002) Submitted.

[11] Jacob F., Olioso A., Weiss M., Baret F., Hautecoeur O., Mapping short-wave albedo of agricultural surfaces using airborne PolDER data, Remote Sensing of Environment 80 (2002) 36-46.

[12] Kimes D., Knyazikhin Y., Privette J., Abuelgasim A., Gao F., Inversion methods for Physically-Based Models, Remote Sensing of Environment 18 (2000) 381-439.

[13] Kustas W., Moran M., Humes K., Stannard D., Pinter P., Hipps L., Swiatek E., Goodrich D., Surface energy balance estimates at local and regional scales using optical remote sensing from an aircraft platform and atmospheric data collected over semiarid rangelands, Water Resources Research 30 (1994) 12411259.

[14] Leroy M., Hautecoeur O., Directional parameters, hemispherical reflectances and angle-corrected NDVIs derived at global scale by the spaceborne PolDER, in: Proceedings of Alps 1999 conference, Méribel, France, January 18-22, 'Land surface' session (Ed. CNES), 1999, pp. 1-4.

[15] Liang S., Narrowband to broadband conversions of land surface albedo I Algorithms, Remote Sensing of Environment 76 (2000) 213-238.

[16] Liang S., Strahler A., Walthall C., Retrieval of land surface albedo from satellite observations: A simulation study, Journal of Applied Meteorology 38 (1999) 712-725.

[17] Lucht W., Expected retrieval accuracies of bidirectional reflectance and albedo from EOS-MODIS and MISR angular sampling, Journal of Geophysical Research 103 (1998) 8763-8778.

[18] Lucht W., Roujean J., Considerations in the parametric modeling of BRDF and albedo from multiangular satellite sensor observations, Remote Sensing Reviews 18 (2000) 343-379. 
[19] Lucht W., Schaaf C., Strahler A., An algorithm for the retrieval of albedo from space using semi-empirical BRDF models, IEEE Transaction on Geoscience and Remote Sensing 38 (2000) 977-977.

[20] Myneni R., Asrar G., Hall F., A three-dimensional radiative transfer method for optical remote sensing of vegetated land surfaces, Remote Sensing of Environment 41 (1992) 105-121.

[21] Olioso A., Braud I., Chanzy A., Ducros Y., Gaudu J., Gonzales-Soza E., Lewan L., Marloie O., Ottlé C., Prévot L., Autret H., Bethenod I., Bonnefond J., Brugier N., Calvet J., Chauki H., Goujet R., Jongschaap R., Kerr Y., Lagouarde J., Laurent J., McAnneney J., Moulin S., Thony J., Weiss M., Wigneron J.-P., SVAT modeling over the Alpilles-ReSeDA experiment: experimental setup for monitoring energy and mass transfers, Agronomie (2002) Submitted.

[22] Olioso A., Chauki H., Courault D., Wigneron J., Estimation of evapotranspiration and photo-synthesis by assimilation of remote sensing data into SVAT models, Remote Sensing of Environment 68 (1999) 341-356.

[23] Olioso A., Prévot L., Baret F., Chanzy A., Braud I., Autret H., Baudin F., Bessemoulin P., Bethenod O., Blamont D., Blavoux B., Bonnefond J., Boubkraoui S., Bouman B., Bruguier N., Calvet J., Caselles V., Chauki H., Clevers J., Coll C., Company A., Courault D., Dedieu G., Degenne P., Delécolle R., Denis H., Desprats J., Ducros Y., Dyer D., Fies J., Fischer A., Francois C., Gaudu J., Gonzalez E., Gouget R., Gu X., Guérif M., Hanocq J., Hautecoeur J., Haverkamp R., Hobbs S., Jacob F., Jeansoulin R., Jongschaap R., Kerr Y., King C., Laborie P., Lagouarde J., Laques A., Larcena D., Laurent G., Laurent J., Leroy M., McAneney J., Macelloni G., Moulin S., Noilhan J., Ottlé C., Paloscia S., Pampaloni P., Podvin T., Quaracino F., Roujean J., Rozier C., Ruisi R., Susini C., Taconet O., Tallet N., Thony J., Travi Y., Van Leewen H., Vauclin M., Vidal-Madjar D., Vonder O., Weiss M., Wigneron J., Spatial aspects in the Alpilles-ReSeDA project, in: Scaling and modeling in forestry: application in remote sensing and GIS, Ed. D.Marceau, Université de Montréal, Québec, 1998, pp. 92-102.

[24] Pragnère A., Baret F., Weiss M., Myneni R., Knyazikhin Y., Wang L., Comparison of three radiative transfer model inversion techniques to estimate 
canopy biophysical variables from remote sensing data, in: Proceedings of IEEE 1999, 28 June - 2 July 1999, Hamburg, volume 2, 1999, pp. 10931095.

[25] Privette J., Eck T., Deering D., Estimating spectral albedo and nadir reflectance through inversion of simple BRDF models with AVHRR/MODIS-like data, Journal of Geophysical Research 102 (1997) 29529-29542.

[26] Prévot L., Baret F., Chanzy A., Olioso A., Wigneron J., Autret H., Baudin F., Bessemoulin P., Bethenod O., Blamont D., Blavoux B., Bonnefond J., Boubkraoui S., Bouman B., Braud I., Bruguier N., Calvet J., Caselles V., Chauki H., Clevers J., Coll C., Company A., Courault D., Dedieu G., Degenne P., Delécolle R., Denis H., Desprats J., Ducros Y., Dyer D., Fies J., Fischer A., Francois C., Gaudu J., Gonzalez E., Gouget R., Gu X., Guérif M., Hanocq J., Hautecoeur J., Haverkamp R., Hobbs S., Jacob F., Jeansoulin R., Jongschaap R., Kerr Y., King C., Laborie P., Lagouarde J., Laques A., Larcena D., Laurent G., Laurent J., Leroy M., McAneney J., Macelloni G., Moulin S., Noilhan J., Ottlé C., Paloscia S., Pampaloni P., Podvin T., Quaracino F., Roujean J., Rozier C., Ruisi R., Susini C., Taconet O., Tallet N., Thony J., Travi Y., Van Leewen H., Vauclin M., Vidal-Madjar D., Vonder O., Weiss M., Assimilation of multi-sensor and multi-temporal remote sensing data to monitor vegetation and soil: the Alpilles ReSeDA project, in: IGARSS'98 International Geoscience and Remote Sensing Symposium, IEEE, Institute of Electrical and Electronics Engineers, Piscataway (USA), Sensing and managing the environment (Ed. L Tsang), volume 5, 1998, pp. 2399-2401.

[27] Rahman H., Dedieu G., SMAC : a Simplified Method for the Atmospheric Correction of satellite measurements in the solar spectrum, International Journal of Remote Sensing 16 (1994) 123-143.

[28] Roujean J., Leroy M., Deschamps P., A bidirectional reflectance model of the Earth's surface for the correction of remote sensing data, Journal of Geophysical Research 97 (1992) 20455-20468.

[29] Sellers P., Remote sensing of the land surface for studies of global change, International Satellite Land Surface Climatology Project Report, NASA/GSFC, Columbia, MD, USA, 1993. 
[30] Song J., Gao W., An improved method to derive surface albedo from narrowband AVHRR satellite data: narrow-band to broadband conversion, Journal of Applied Meteorology 38 (1999) 239-249.

[31] Strahler A., Schaaf C., Muller J.-P., Wanner W., Barnsley M., d'Entremont R., B. H., Lewis P., Li X., Ruise De Lope E., MODIS BRDF / Albedo product: Algorithm Theoretical Basis Document, NASA EOS-MODIS Doc. Incl. Update, version 4.0, NASA/GSFC, Greenbelt MD, USA, 1996.

[32] Varlet-Grancher C., Bonhomme R., Chartier M., Artis P., Efficience de la conversion de l'énergie solaire par un couvert végétal, Acta oecologica. Oecologica Plantarum 17 (1982) 3-26.

[33] Verhoef W., Earth observation modeling based on layer scattering matrices, Remote Sensing of Environment 17 (1985) 165-178.

[34] Vermote E., Tanré D., Deuzé J., Morcrette J., Second simulation of the satellite signal in the solar spectrum: an overview, IEEE Transactions on Geoscience and Remote Sensing 35 (1997) 675-686.

[35] Walthall C., Norman J., Welles G., Campbell G., Blad G., Simple equation to approximate the bidirectional reflectance from vegetative canopies and bare soil surfaces, Applied Optics 24 (1985) 383-387.

[36] Walthall C., Roujean J., Morisette J., Field and landscape BRDF optical wavelength measurements: experiences, technique and the future, Remote Sensing Reviews 18 (2000) 503-531.

[37] Wanner W., Li X., Strahler A., On the derivation of kernels for kernel-driven models of bidirectional reflectance, Journal of Geophysical Research 100 (1995) 21077-21089.

[38] Wanner W., Strahler A., Hu B., Lewis P., Muller J.-P., Li X., Barker Schaaf C., Barnsley M., Global retrieval of bidirectional reflectance and albedo over land from EOS MODIS and MISR data: theory and algorithm., Journal of Geophysical Research 102 (1997) 17143-17161.

[39] Weiss M., Baret F., Leroy M., Bégué A., Hautecoeur O., Santer R., Hemispherical reflectance and albedo estimate from the accumulation of across- 
track sun-synchronous satellite data, Journal of Geophysical Research 104 (1999) 22221-22232.

[40] Weiss M., Jacob F., Baret F., Pragnère A., Leroy M., Hautecoeur O., Prévot L., Bruguier N., Evaluation of kernel-driven BRDF models for the normalization of Alpilles/ReSeDA PolDER data, Agronomie (2002) Accepted. 


\section{List of Figures}

1 Comparison between field and airborne shortwave albedo considering the Li-Ross model and coefficient set $n^{0} 6$. . . . . . . . . .

2 The same as Fig 1 when calculating shortwave albedo from the Eq. 3 with a $k$ value about 0.55 , the hemispherical reflectance computed with the Walthall model, and $a_{v i s}$ (respectively $a_{N I R}$ ) computed from set $\mathrm{n}^{0} 7$ (respectively 8 ). . . . . . . . . . . 31 


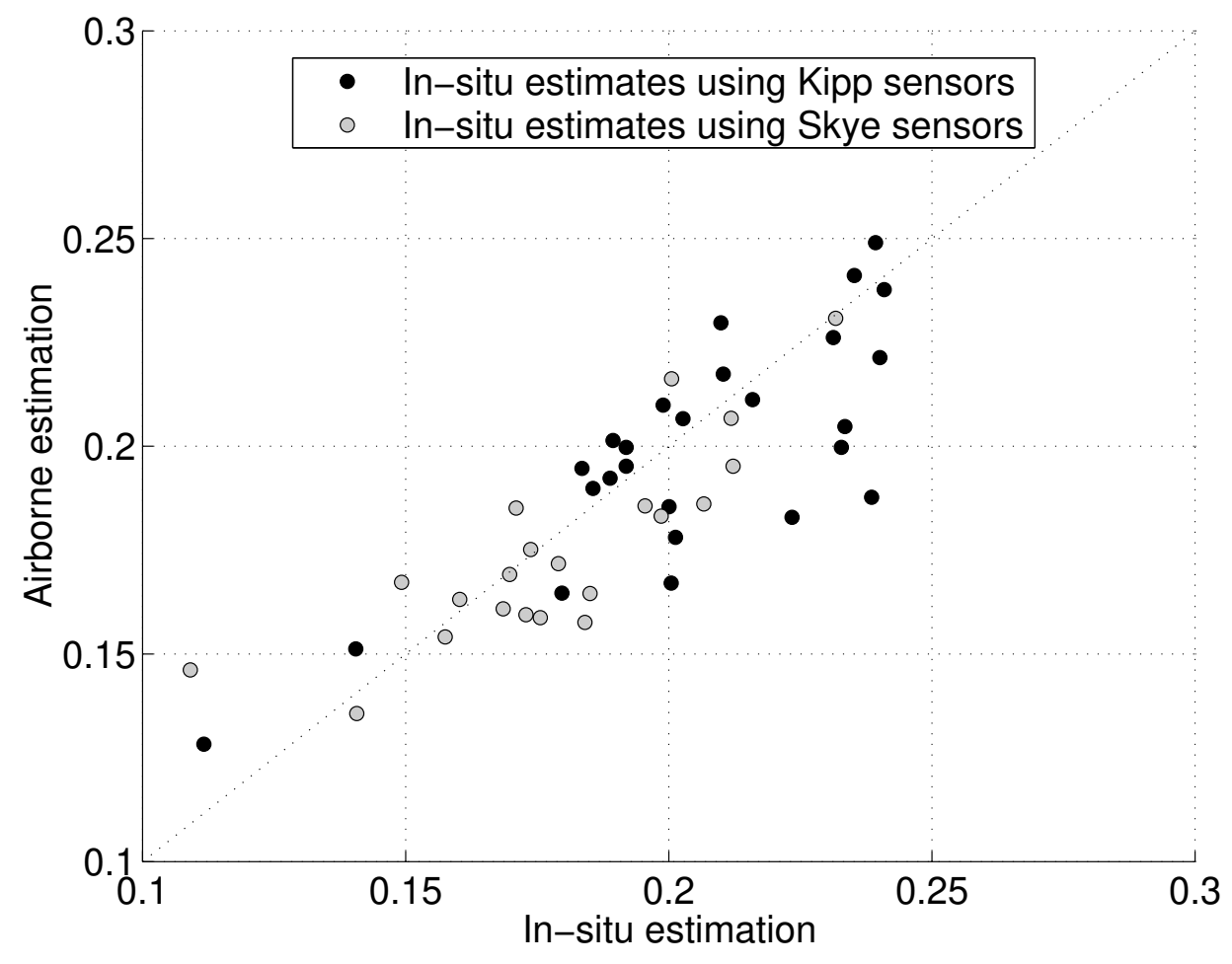

Figure 1: Comparison between field and airborne shortwave albedo considering the Li-Ross model and coefficient set $n^{0} 6$. 


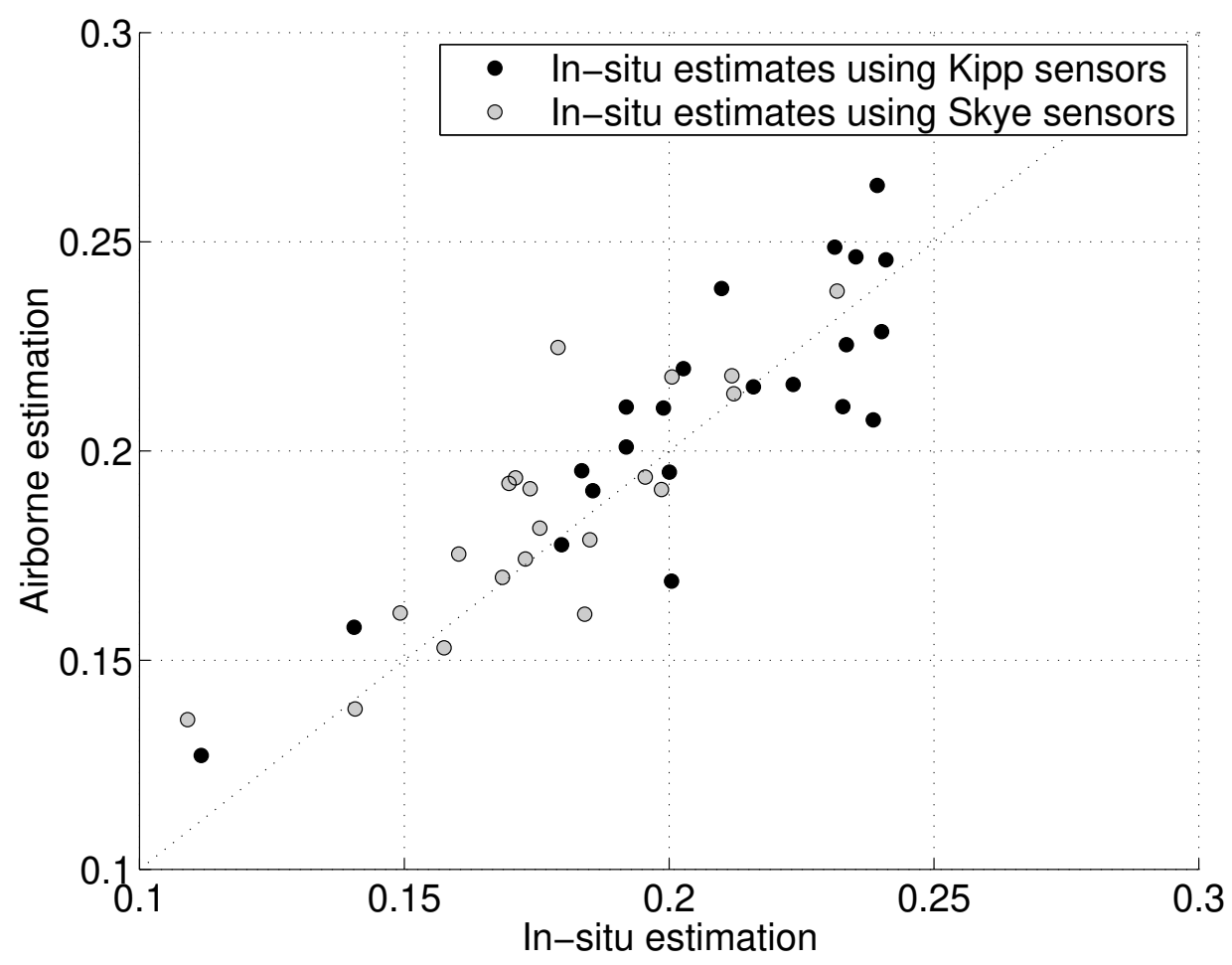

Figure 2: The same as Fig 1 when calculating shortwave albedo from the Eq. 3 with a $k$ value about 0.55 , the hemispherical reflectance computed with the Walthall model, and $a_{v i s}$ (respectively $a_{N I R}$ ) computed from set $\mathrm{n}^{\mathrm{o}} 7$ (respectively 8). 


\section{List of Tables}

1 Comparison between the hemispherical reflectance estimates from Li-Ross and MRPV according to the four PolDER channels. Corr. Coef. means Correlation Coefficient. Results extracted from Jacob et al. [11]. . . . . . . . . . . . . . . . . . . . .

2 Percentage of pixels rejected over the study area to remove the unrealistic value of hemispherical reflectance provided by the kerneldriven models. . . . . . . . . . . . . . . . . . . . .

3 Sets of coefficients used to compute the albedo as a linear combination of waveband hemispherical reflectance. Albedo is labeled as Vis, NIR, SW / A, I for respectively Visible, Near InfraRed, ShortWave / Apparent, Inherent albedo. The waveband limits (in $\mathrm{nm}$ ) indicate the wavelengths Weiss et al. [39] considered for generic sensors with sets $\mathrm{n}^{\mathrm{O}} 1$ to 3 ; the nominal wavebands Liang et al. [16] and Liang [15] considered for the MISR sensor with sets $\mathrm{n}^{\mathrm{O}} 4$ to 6 , and sets $\mathrm{n}^{0} 7$ to 9 respectively; and the channel of the airborne PolDER (A / C PolDER) during the ReSeDA experiment. . . . . . .

4 Comparison between shortwave albedo estimates from the four kernel-driven models along with set $n^{0} 6 \ldots . . . \ldots$. . . . .

5 Comparison between shortwave albedo estimates from the four coefficient sets along with the Li-Ross kernel-driven model. . . . . .

6 Absolute \& relative RMSE and Bias between airborne and field estimates of shortwave albedo. Hemispherical reflectance was estimated using Walthall model. Sets $\mathrm{n}^{\mathrm{O}} 4+5$ and $\mathrm{n}^{\mathrm{O}} 7+8$ were used along with a $\mathrm{k}$ value about 0.55 .

7 Absolute and relative RMSE and Bias between airborne and field estimates of shortwave apparent albedo. We considered sets $\mathrm{n}^{0} 7$ and 8 along with a $k$ value about $0.55 \ldots \ldots \ldots \ldots$

8 Correlation coefficient matrix of the hemispherical reflectances over the four PolDER channels provided by the Li-Ross model. . . . .

9 Values of the calibrated coefficients (coef) obtained from linear regressions between the field data of albedo and the PolDER hemispherical reflectance estimates. The associated $90 \%$ confidence intervals (co. in.) are given below the coefficients with the \pm sign. The corresponded residual errors as given through ARMSE and RRMSE. . . . . . . . . . . . . . . . . . . . . . . 


\begin{tabular}{l||c|c|c|c} 
Channel & $\begin{array}{c}\text { Blue } \\
(443 \mathrm{~nm})\end{array}$ & $\begin{array}{c}\text { Green } \\
(550 \mathrm{~nm})\end{array}$ & $\begin{array}{c}\text { Red } \\
(670 \mathrm{~nm})\end{array}$ & $\begin{array}{c}\text { NIR } \\
(865 \mathrm{~nm})\end{array}$ \\
\hline \hline ARMSD & 0.0078 & 0.0098 & 0.0124 & 0.0295 \\
\hline RRMSD & $12.8 \%$ & $8.1 \%$ & $10.0 \%$ & $8.3 \%$ \\
\hline Corr. Coef. & 0.9671 & 0.9891 & 0.9907 & 0.9851
\end{tabular}

Table 1: Comparison between the hemispherical reflectance estimates from LiRoss and MRPV according to the four PolDER channels. Corr. Coef. means Correlation Coefficient. Results extracted from Jacob et al. [11]. 


\begin{tabular}{c||c|c|c|c} 
Model & Blue & Green & Red & NIR \\
\hline \hline Li-Ross & $8.5 \%$ & $1.2 \%$ & $1.6 \%$ & $0.2 \%$ \\
\hline MRPV & $6.1 \%$ & $0.7 \%$ & $0.7 \%$ & $0.4 \%$ \\
\hline Roujean & $15.0 \%$ & $3.4 \%$ & $5.1 \%$ & $0.5 \%$ \\
\hline Walthall & $12.0 \%$ & $2.0 \%$ & $2.1 \%$ & $0.3 \%$
\end{tabular}

Table 2: Percentage of pixels rejected over the study area to remove the unrealistic value of hemispherical reflectance provided by the kernel-driven models. 


\begin{tabular}{|c|c|c|c|c|c|c|}
\hline $\begin{array}{l}\text { Author } \\
\text { \& Albedo }\end{array}$ & $\begin{array}{l}\text { Sensor } \\
\& \text { Set }\end{array}$ & \multicolumn{4}{|c|}{$\begin{array}{c}\text { Wavebands } \\
\text { \& Coefficient values }\end{array}$} & \multirow[t]{2}{*}{ Offset } \\
\hline $\begin{array}{l}\text { Weiss et al. } \\
\text { [39] }\end{array}$ & Generic & 445 & 560 & 665 & 855 & \\
\hline SW / A & Set $n^{0} 1$ & - & - & 0.57 & 0.46 & - \\
\hline SW / A & Set $n^{0} 2$ & - & 0.68 & 0.08 & 0.35 & - \\
\hline SW / A & Set $n^{0} 3$ & 0.06 & 0.69 & 0.001 & 0.35 & - \\
\hline $\begin{array}{l}\text { Liang et al. } \\
\qquad[16]\end{array}$ & MISR & $426-467$ & $544-571$ & $662-682$ & $847-886$ & \\
\hline Vis / I & Set $n^{\circ} 4$ & 0.3511 & 0.3923 & 0.2603 & - & -0.0030 \\
\hline NIR / I & Set $n^{0} 5$ & - & - & - & 0.6088 & 0.1442 \\
\hline $\mathrm{SW} / \mathrm{I}$ & Set $^{0} 6$ & 0.1587 & -0.2463 & 0.5442 & 0.3748 & 0.0149 \\
\hline $\begin{array}{c}\text { Liang } \\
{[15]}\end{array}$ & MISR & $426-467$ & $544-571$ & $662-682$ & $847-886$ & \\
\hline Vis / A & Set $n^{0} 7$ & 0.3810 & 0.3340 & 0.2870 & - & - \\
\hline NIR / A & Set $n^{0} 8$ & -0.3870 & -0.1960 & 0.5040 & 0.8300 & 0.0110 \\
\hline \multirow[t]{2}{*}{ SW / A } & Set $n^{\circ} 9$ & - & 0.1260 & 0.3430 & 0.4150 & 0.0037 \\
\hline & $\begin{array}{c}\text { A / C } \\
\text { PolDER }\end{array}$ & $423-463$ & $530-570$ & $650-690$ & $845-885$ & \\
\hline
\end{tabular}

Table 3: Sets of coefficients used to compute the albedo as a linear combination of waveband hemispherical reflectance. Albedo is labeled as Vis, NIR, SW / A, I for respectively Visible, Near InfraRed, ShortWave / Apparent, Inherent albedo. The waveband limits (in $\mathrm{nm}$ ) indicate the wavelengths Weiss et al. [39] considered for generic sensors with sets $n^{0} 1$ to 3 ; the nominal wavebands Liang et al. [16] and Liang [15] considered for the MISR sensor with sets $n^{\circ} 4$ to 6 , and sets $n^{0} 7$ to 9 respectively; and the channel of the airborne PolDER (A / C PolDER) during the ReSeDA experiment. 


\begin{tabular}{c|c||c|c|c} 
First model & Second model & ARMSD & RRMSD & Corr coef. \\
\hline \hline Li-Ross & MRPV & 0.0127 & $6.6 \%$ & 0.9560 \\
\hline MRPV & Roujean & 0.0091 & $4.7 \%$ & 0.9746 \\
\hline Roujean & Walthall & 0.0133 & $6.8 \%$ & 0.9025
\end{tabular}

Table 4: Comparison between shortwave albedo estimates from the four kerneldriven models along with set $n^{0} 6$. 


\begin{tabular}{c|c||c|c|c} 
First set & Second set & ARMSD & RRMSD & Corr coef. \\
\hline \hline Set $\mathrm{n}^{\mathrm{o}} 1$ & Set $^{\mathrm{o}} 2$ & 0.0179 & $8.3 \%$ & 0.9594 \\
\hline Set $\mathrm{n}^{\mathrm{o}} 2$ & Set $^{\mathrm{o}} 3$ & 0.0055 & $2.7 \%$ & 0.9963 \\
\hline Set $\mathrm{n}^{\mathrm{o}} 3$ & Set $^{\mathrm{o}} 6$ & 0.0202 & $10.3 \%$ & 0.9374 \\
\hline Set $\mathrm{n}^{\mathrm{o}} 6$ & Set $^{\mathrm{o}} 9$ & 0.0154 & $7.9 \%$ & 0.9744
\end{tabular}

Table 5: Comparison between shortwave albedo estimates from the four coefficient sets along with the Li-Ross kernel-driven model. 


\begin{tabular}{c||cc|cc}
$\begin{array}{c}\text { BRDF Model } \\
\text { \& Coefficient set }\end{array}$ & ARMSE & RRMSE & ABias & RBias \\
\hline \hline Walthall \& set $\mathrm{n}^{\mathrm{o}} 1$ & 0.0417 & $21.4 \%$ & 0.0360 & $18.5 \%$ \\
\hline Walthall \& set $\mathrm{n}^{\mathrm{0}} 2$ & 0.0282 & $14.5 \%$ & 0.0180 & $9.3 \%$ \\
\hline Walthall \& set $\mathrm{n}^{0} 3$ & 0.0255 & $13.2 \%$ & 0.0187 & $9.7 \%$ \\
\hline Walthall \& set $\mathrm{n}^{\circ} 4+5$ & 0.0280 & $14.5 \%$ & 0.0224 & $11.6 \%$ \\
\hline Walthall \& set $\mathrm{n}^{\circ} 6$ & 0.0160 & $8.3 \%$ & 0.0003 & $0.2 \%$ \\
\hline Walthall \& set $\mathrm{n}^{0} 7+8$ & 0.0164 & $8.5 \%$ & 0.0049 & $2.5 \%$ \\
\hline Walthall \& set $\mathrm{n}^{\circ} 9$ & 0.0248 & $12.8 \%$ & 0.0145 & $7.4 \%$
\end{tabular}

Table 6: Absolute \& relative RMSE and Bias between airborne and field estimates of shortwave albedo. Hemispherical reflectance was estimated using Walthall model. Sets $n^{0} 4+5$ and $n^{0} 7+8$ were used along with a $k$ value about 0.55 . 


\begin{tabular}{c||c|c|c|c} 
BRDF model & ARMSE & RRMSE & ABias & RBias \\
\hline \hline Li-Ross & 0.0168 & $8.7 \%$ & -0.0012 & $-0.6 \%$ \\
\hline MRPV & 0.0227 & $11.6 \%$ & 0.0118 & $6.1 \%$ \\
\hline Roujean & 0.0231 & $12.0 \%$ & 0.0073 & $3.8 \%$ \\
\hline Walthall & 0.0164 & $8.5 \%$ & 0.0049 & $2.5 \%$
\end{tabular}

Table 7: Absolute and relative RMSE and Bias between airborne and field estimates of shortwave apparent albedo. We considered sets $\mathrm{n}^{\mathrm{0}} 7$ and 8 along with a $k$ value about 0.55 . 


\begin{tabular}{|c|c|c|c|c|}
\hline & $\rho_{h, 443}$ & $\rho_{h, 550}$ & $\rho_{h, 670}$ & $\rho_{h, 865}$ \\
\hline$\rho_{h, 443}$ & 1.0000 & 0.9202 & 0.8938 & -0.5683 \\
\hline$\rho_{h, 550}$ & 0.9202 & 1.0000 & 0.9443 & -0.5549 \\
\hline$\rho_{h, 670}$ & 0.8938 & 0.9443 & 1.0000 & -0.7244 \\
\hline$\rho_{h, 865}$ & -0.5683 & -0.5549 & -0.7244 & 1.0000 \\
\hline
\end{tabular}

Table 8: Correlation coefficient matrix of the hemispherical reflectances over the four PolDER channels provided by the Li-Ross model. 


\begin{tabular}{|c|c|c|c|c|c|c|}
\hline & blue & green & red & NIR & & \\
\hline BRDF & coef & coef & coef & coef & offset & ARMSE \\
\hline Model & co. in. & co. in. & co. in. & co. in. & co. in. & RRMSE \\
\hline \multirow{2}{*}{ LSRK } & - & - & 0.5912 & 0.3737 & -0.0008 & 0.0155 \\
\hline & - & - & \pm 0.1199 & \pm 0.0533 & \pm 0.0291 & $8.04 \%$ \\
\hline \multirow{2}{*}{ LSRK } & - & -0.2659 & 0.8118 & 0.3978 & -0.0025 & 0.0153 \\
\hline & - & \pm 0.4158 & \pm 0.3651 & \pm 0.0652 & \pm 0.0292 & $7.94 \%$ \\
\hline \multirow{2}{*}{ LSRK } & -0.3867 & -0.2205 & 1.0044 & 0.4122 & -0.0114 & 0.0147 \\
\hline & \pm 0.3488 & \pm 0.4066 & \pm 0.3954 & \pm 0.0648 & \pm 0.0295 & $7.63 \%$ \\
\hline \multirow{2}{*}{ MRPV } & - & - & 0.5836 & 0.3483 & -0.0037 & 0.0173 \\
\hline & - & - & \pm 0.1349 & \pm 0.0574 & \pm 0.0346 & $8.91 \%$ \\
\hline \multirow{2}{*}{ MRPV } & - & 0.1029 & 0.4950 & 0.3384 & -0.0022 & 0.0173 \\
\hline & - & \pm 0.3845 & \pm 0.3580 & \pm 0.0687 & \pm 0.0354 & $8.89 \%$ \\
\hline \multirow{2}{*}{ MRPV } & -0.2247 & 0.1436 & 0.5766 & 0.3324 & -0.0017 & 0.0170 \\
\hline & \pm 0.3211 & \pm 0.3873 & \pm 0.3752 & \pm 0.0690 & \pm 0.0352 & $8.76 \%$ \\
\hline \multirow{2}{*}{ Roujean } & - & - & 0.5794 & 0.3253 & 0.0110 & 0.0187 \\
\hline & - & - & \pm 0.1488 & \pm 0.0591 & \pm 0.0350 & $9.69 \%$ \\
\hline \multirow{2}{*}{ Roujean } & - & -0.1720 & 0.7189 & 0.3415 & 0.0101 & 0.0186 \\
\hline & - & \pm 0.4912 & \pm 0.4257 & \pm 0.0755 & \pm 0.0354 & $9.64 \%$ \\
\hline \multirow{2}{*}{ Roujean } & -0.5609 & -0.0910 & 0.9673 & 0.3527 & 0.0008 & 0.0177 \\
\hline & \pm 0.4812 & \pm 0.4787 & \pm 0.4625 & \pm 0.0734 & \pm 0.0350 & $9.17 \%$ \\
\hline \multirow{2}{*}{ Walthall } & - & - & 0.4822 & 0.3567 & 0.0087 & 0.0152 \\
\hline & - & - & \pm 0.1036 & \pm 0.0494 & \pm 0.0271 & $7.92 \%$ \\
\hline \multirow{2}{*}{ Walthall } & - & 0.0024 & 0.4803 & 0.3565 & 0.0087 & 0.0152 \\
\hline & - & \pm 0.4665 & \pm 0.3895 & \pm 0.0658 & \pm 0.0276 & $7.92 \%$ \\
\hline \multirow{2}{*}{ Walthall } & -0.5934 & 0.2937 & 0.6170 & 0.3605 & -0.0076 & 0.0144 \\
\hline & \pm 0.4667 & \pm 0.5017 & \pm 0.3879 & \pm 0.0631 & \pm 0.0294 & $7.48 \%$ \\
\hline
\end{tabular}

Table 9: Values of the calibrated coefficients (coef) obtained from linear regressions between the field data of albedo and the PolDER hemispherical reflectance estimates. The associated $90 \%$ confidence intervals (co. in.) are given below the coefficients with the \pm sign. The corresponded residual errors as given through ARMSE and RRMSE. 